\begin{tabular}{|l|l|l|l|l|l|}
\hline J. Tek. Ling & Vol. 12 & No. 3 & Hal. 251 - 258 & Jakarta, September 2011 & ISSN 1441-318X \\
\hline
\end{tabular}

\title{
PENELITIAN TINGKAT TOKSISITAS PRODUK KOMPONEN BANGUNAN DARI BAHAN DRILL CUTTING
}

\author{
Andriati Amir Husin (andriatiamir@yahoo.com) \\ Lasino (Isn_pu@yahoo.com) \\ Bambang Sugiharto (bambangbob@gmail.com)
}

Peneliti pada Pusat Litbang Permukiman, Balitbang-Kementrian PU

\begin{abstract}
Abstrak
Sumber daya panas bumi adalah salah satu sumber energi paling potensial di dunia. Dan salah satu produk samping panas bumi aktivitas pengeboran sumur adalah dalam bentuk pasir berlumpur. Ini berisi bahan kimia tertentu yang dapat mencemari lingkungan jika tidak ditangani dan direncanakan secara baik. Produk penyebaranPemotongan Bor termasuk dalam kategori limbah berbahaya dan beracun berdasarkan Peraturan Pemerintah no 85 (1999). Namu demikian produk sampai tersebut dapat digunakan kembali dengan ketentuan bahwa logam berat yang terkandung kontaminan berada pada tingkat yang dapat diterima berdasarkan uji kronis sub. Hal ini karena pemotongan bor tidak aman bagi organisme hidup dan kesehatan manusia. Dalam penelitian ini kami menganalisis kontaminasi logam berat dengan mengekstraksi TCLP dari beberapa komponen bangunan seperti blok beton berongga, genteng beton, paving blok dan panel beton. Pemotongan bor konten yang digunakan adalah $60 \%$ untuk blok beton berongga, genteng beton, panel beton dan $40 \%$ untuk paving block. Hasil penelitian menunjukkan bahwa kandungan logam berat dalam komponen bangunan yang diuji berada di bawah tingkat batas toleransi dan karena itu dapat diterima.
\end{abstract}

kata kunci: limbah panas bumi, pemotongan bor, komponen bangunan, toksisitas, lingkungan

\begin{abstract}
Geothermal resources is one of the most potential energy resources in the world. And one of side products of geothermal well drilling activities is drill cutting in the form of muddy sand. It contains particular chemical ingredient which can pollute environment if is not well handle and planned. Drill cutting falls into category of hazardous and toxic waste based on the government regulation no 85 (1999). It can be reused under the condition that heavy metal contaminant contained is at an acceptable level based on a sub chronic test. In this research we analyzed heavy metal contamination by extracting TCLP of some building components like hollow concrete block, concrete tile, paving block and concrete panel. The drill cutting content used was $60 \%$ for hollow concrete block, concrete tile, concrete panel and $40 \%$ for paving block. The experiment result demonstrates that heavy metal content in the tested building components are below the tolerable limit level and is therefore acceptable.
\end{abstract}

key words: geothermal waste, drill cutting, building component, toxicity, environment. 


\section{PENDAHULUAN}

\subsection{Latar Belakang}

Kesejahteraan manusia pada saat ini sangat ditentukan oleh ketersediaan, jumlah, harga dan mutu energi yang dapat dimanfaat-kannya. Energi juga merupakan unsur penunjang utama dalam pertumbuhan ekonomi yang mempengaruhi pertumbuhan sektor lainnya. Pembangunan ekonomi yang melibatkan kekayaan bumi harus memperhatikan pengelolaan sumber daya alam yang dapat memberikan manfaat untuk saat ini dan masa datang. Peran energi sangat penting dalam kehidupan manusia dan proses pembangunan, oleh karena itu pembangunan energi harus dilaksanakan secara berdaya guna.

Produktifitas dan konsumsi energi nasional akhir-akhir ini cenderung meningkat secara konsisten. Indonesia memiliki cadangan sumber energi yang cukup banyak dan beragam. Panas bumi berpeluang dikembangkan untuk menghemat pengeluaran dan pembelian bahan bakar minyak atau batubara dan lebih ramah lingkungan.

Eksploitasi panas bumi saat ini sudah dilakukan dengan pengeboran sumur-sumur geothermal bersamaan dengan meningkatnya kebutuhan sumber energi, sehingga berpotensi menghasilkan limbah yang cukup banyak. Pengeboran sumur-sumur geothermal mengha-silkan berbagai macam limbah. Salah satu limbah yang dihasilkan dalam jumlah yang besar adalah drill cutting berupa pasir berlumpur, mengandung bahan kimia tertentu dan dapat mencemari lingkungan bila tidak ditangani dengan baik. Berdasarkan uraian di atas maka dalam rangka penanganan permasalah tersebut perlu dilakukan penelitian pemanfaatan drill cutting limbah pengeboran sumur geothermal' ${ }^{1}$.

Pemanfaatan energi panas bumi secara konvensioanal dilakukan dengan melakukan pemboran (drilling) pada sumursumur bor, seperti layaknya sumur-sumur minyak. Bila sumur-sumur ini ditajak sampai mencapai pada kedalaman tertentu, maka akan diperoleh zona sumber panas uap (productive geothermal zone) atau disebut juga sebagai geothermal reservoirs yang berisi air panas dan uap panas. Temperatur uap di dalam reservoirs dapat mencapai $240^{\circ} \mathrm{C}$, dimana pada temperatur ini uap telah mencapai uap sangat jenuh (superheated steam). Uap panas dari reservoirs akan dengan mudah mengalir ke permukaan melalui lubang bor untuk selanjutnya dialirkan ke proses pembangkit listrik (power plant). Salah satu yang dihasilkan dari kegiatan operasional Pusat Listrik Tenaga Panas Bumi adalah drill cutting dari kegiatan pemboran. Limbah drill cutting dapat dimanfaatkan sebagai pengganti agregat halus untuk konstruksi beton ringan. Untuk itu dilakukan kajian guna memastikan pemanfaatan drill cutting tersebut tidak akan merusak kualitas lingkungan. Limbah drill cutting dapat dimanfaatkan untuk saluran drainase, blok beton dan batako. Produk tersebut dipilih karena telah mengalami proses solidifikasi sehingga aman lingkungan.

Analisa TCLP (Toxicity Characteristic Leaching Procedure) adalah suatu metode analitik untuk menstimulasi limbah $\mathrm{B}_{3}$ yang akan atau telah di-landfilling dalam kondisi ekstrim terjadi lindi (leachate). Metode uji ini digunakan sebagai salah satu penentuan karakteristik limbah $B_{3}$ di Indonesia untuk kategori beracun, bersasaran untuk menentukan mobilitas pencemar organik/anorganik yang berada pada limbah cair, padat dan multi phase. Khaerunisa telah melakukan penelitian toksisitas limbah batubara dari Sumatera dan Kalimantan terhadap kutu air, ikan mas dan mencit ternyata bahan limbah batubara tidak berbahaya bagi mahluk hidup ${ }^{2}$. Begitu juga Dhahiyat telah melakukan uji toksisitas RCC (Residual Catalytic Cracking) terhadap mencit.Ternyata tidak menyebabkan kematian pada mencit tersebut baik mencit jantan maupun mencit betina ${ }^{3)}$. Limbah batubara dan RCC termasuk 
ke dalam limbah $\mathrm{B}_{3}$. Berdasarkan PP No. 02/2008 limbah $B_{3}$ adalah sisa suatu usaha dan/atau kegiatan yang mengandung bahan berbahaya dan/atau beracun yang karena sifat dan/atau konsentrasinya dan/atau jumlahnya, baik secara langsung maupun tidak langsung dapat mencemarkan dan/ atau merusak lingkungan hidup, dan/atau dpat membahayakan lingkungan hidup, kesehatan, kelangsungan hidup manusia serta makhluk hidup lainnya ${ }^{7}$.

Metode uji pelindian (leaching) yang perlu dilakukan terhadap perlakuan limbah $\mathrm{B}_{3}$, secara umum bertujuan meminimalisasi jumlah volume dan kuantitas $B_{3}$ yang ditimbulkan, diolah, disimpan atau dibuang.

MenurutPP 18/1999, penentuan apakah sebuah limbah disebut beracun (toxic) yaitu melalui uji Toxicity Characteristic Leaching Prosedure) (TCLP). Uji TCLP ini merupakan uji pelindian yang berlaku secara federal di Amerika Serikat, sesuai dengan RCRA yang mengatur tentang hazardous waste management. Disamping sebagai penentuan salah satu sifat berbahaya dari limbah, uji TCLP diterapkan pula dalam evaluasi produk pretreatment limbah sebelum di landfilling, yaitu proses solidifikasi/ stabilisasi (S/S). Di Amerika Serikat limbah yang dikatagorikan berbahaya, tidak diperkenankan dimasukkan dalam kondisi air. Limbah tersebut terlebih dahulu harus berada dalam kondisi matrik padat, yaitu melalui proses S/S. Konsep ini juga diadopsi oleh Indonesia melalui Kep. Bapedal 03/Bapedal/09/954).

Menurut Sumarwoto setiap hasil produksi suatu industri yang terbuang dapat dimanfaatkan kembali untuk menghasilkan bahan baku bagi produk yang lain sehingga limbah yang dihasil-kan dapat didaur ulang (recycle), diguna ulang (reuse) dan direduksi (reduce) $)^{5}$.

Dewasa ini di Indonesia mulai dikembangkan pembangunan industri yang didasariazas eco-efficiency yaitu meminimalkan produksi limbah persatuan produk, yang artinya mulai dari penggunaan materi dan energi diupayakan semi-nimal mungkin, sehingga prinsip 3R sering kali digunakan dalam proses ecoefficiency tersebut ${ }^{4}$.

Upaya pemanfaatan limbah drill cuttin sebagai bahan subsitusi dalam campuran elemen bangunan, pada prinsipnya merupakan proses stabilisasi/solidifikasi (S/S). Keuntungan yang didapat antara lain akan meningkatkan nilai komersial dan daya guna dari limbah tersebut, selain itu dapat menghemat pemakaian sumber material alam yang tidak terbaharukan (non renewable).

\subsection{Tujuan}

Penelitian ini bertujuan untuk membuktikan bahwa drill cutting yang dikembangkan untuk bahan bangunan tidak mengandung limbah $B_{3}$ yang membahayakan.

\section{METODOLOGI}

Metoda penelitian yang digunakan adalah metoda eksperimental dengan melakukan pembuatan benda uji di laboratorium dari berbagai komponen bangunan (bata beton berlobang, genteng beton, paving block dan panel beton) dan variasi campuran untuk dilakukan analisis terhadap tingkat toksisitasnya dengan menggunakan metoda toxicity characteristic leaching procedure (TCLP). Hasil penelitian dapat ditunjukkan secara langsung berdasarkan unsur kimia yang terkandung dari masing-masing contoh uji berdasarkan baku mutu yang disyaratkan.

Dalam upaya mencapai tujuan dan sasaran dari penelitian ini, perlu dirancang suatu langkah-langkah yang tepat dengan diawali kegiatan inventarisasi standar atau metoda yang akan digunakan sebagai acuan dalam pengujian, Secara rinci langkah kegiatan tersebut dapat diuraikan sebagai berikut:

\subsection{Bahan dan alat}

Bahan-bahan yang digunakan untuk campuran komponen bangunan meliputi pasir 
dari Cimalaka Sumedang, semen Portland dan air bersih dari laboratorium Puskim. Sedangkan perlatan yang digunakan dalam penelitian ini adalah peralatan Laboratorium Bahan Bangunan yang meliputi mesin aduk (mixer), mesin cetak dan alat bantu lainnya

\subsection{Tempat dan waktu penelitian}

Penelitian dilaksanakan di laboratorium Balai Bahan Bangunan, Pusat Penelitian dan Pengembangan Permukiman Bandung dan di Laboratorium Lingkungan Universitas Padjadjaran Bandung pada tahun 2006.

\subsection{Sampling dan analisis sample}

Bahan-bahan yang diperlukan dalam pene-litian ini adalah semen Portland, pasir dari Cimalaka-Sumedang, drill cutting dan air bersih dari Laboratorium Puskim. Alat-alat yang diperlukan dalam penelitian ini adalah ayakan, timbangan, gelas ukur, mixer, cetakan untuk bata beton berlobang, paving block, genteng beton dan panel, alat tumbuk, seperangkat alat ekstraksi, teflon dan alat uji AAS.

Metode yang digunakan dalam penelitian ini adalah metode eksperimental dengan membuat contoh uji berupa bata beton berlobang, genteng beton, paving block dan panel beton. Komposisi campuran yang digunakan dihitung dalam berat.(lihat tabel 1).
Prosedur pengujian TCLP

- Tumbuk contoh uji drill cutting, bata beton berlobang, genteng beton, panel beton dan paving block

- Ayak contoh uji dengan menggunakan ayakan No.100

- Timbang contoh uji masing-masing sebanyak 25 gram

- Larutkan contoh uji dalam larutan asam asetat pada $\mathrm{pH} 3$ tambahkan larutan asam asetat sampai volumenya $100 \mathrm{~mL}$ kemudian ekstrak dengan menggunakan alat pengekstrak dengan kecepatan sudut putaran $(30+/-2) \mathrm{rpm}$

- Saring larutan yang telah diekstrak dengan menggunakan microfiber filter yang mempunyai porositas kapiler 0,6-0,7 millimikron

- Simpan larutan di dalam botol Teflon sebelum dilakukan pengujian

- Uji larutan uji dengan menggunakan alat Atomic Absorption Spectrophotometer (AAS)

- Pengujian AAS dilakukan di laboratorium Lingkungan UNPAD

\section{HASIL DAN PEMBAHASAN}

Hasil analisis kimia dari drill cutting, bata beton berlobang, genteng beton, paving block dan panel beton dapat dilihat pada tabel 2 sampai tabel 6 beton dapat dilihat pada tabel 2 sampai tabel 6 .

Tabel 1. Komposisi campuran komponen bangunan

\begin{tabular}{|c|c|c|c|}
\hline \multirow{3}{*}{ Komponen bangunan } & \multicolumn{3}{|c|}{ Campuran } \\
\hline & \multirow[t]{2}{*}{ Semen Portland } & \multicolumn{2}{|c|}{ Agregat } \\
\hline & & Drill cutting (\%) & Pasir (\%) \\
\hline \multirow[t]{2}{*}{ Bata beton berlobang } & \multirow[t]{2}{*}{1} & \multicolumn{2}{|c|}{8} \\
\hline & & 60 & 40 \\
\hline \multirow[t]{2}{*}{ Genteng beton } & \multirow[t]{2}{*}{1} & \multicolumn{2}{|c|}{2} \\
\hline & & 60 & 40 \\
\hline \multirow[t]{2}{*}{ Panel beton } & \multirow[t]{2}{*}{1} & \multicolumn{2}{|c|}{3} \\
\hline & & 60 & 40 \\
\hline Paving block & Kekuatan $200 \mathrm{~kg} / \mathrm{cm}^{2}$ & 40 & 60 \\
\hline
\end{tabular}


Tabel 2. Hasil analisis kimia drill cutting

\begin{tabular}{|c|c|c|c|c|c|}
\hline No. & Unsur & Satuan & Pure waste & On waste & PP No. $18 / 1999(\text { TCLP) })^{6}$ \\
\hline 1. & Sianida $(\mathrm{CN})$ & $\mathrm{Ppm}$ & $<0,004$ & - & 1 \\
\hline 2. & Nitrat $\left(\mathrm{HNO}_{3}\right)+$ Nitrit $\left(\mathrm{HNO}_{2}\right)$ & Ppm & 0,86 & - & 500 \\
\hline 3. & Nitrit $\left(\mathrm{HNO}_{2}\right)$ & Ppm & $<0,062$ & - & 50 \\
\hline 4. & Arsen (As) & Ppm & $<0,003$ & 6,48 & 0,2 \\
\hline 5. & Barium $(\mathrm{Ba})$ & Ppm & 0,20 & 433,36 & 5 \\
\hline 6. & Boron (B) & $\mathrm{Ppm}$ & $<0,07$ & - & 100 \\
\hline 7. & Krom (Cr) & $\mathrm{Ppm}$ & $<0,02$ & 2,06 & 0,25 \\
\hline 8. & Tembaga $(\mathrm{Cu})$ & Ppm & 0,047 & 41,45 & 0,19 \\
\hline 9. & Merkuri $(\mathrm{Hg})$ & $\mathrm{Ppm}$ & 0,00060 & 0,33153 & 0,01 \\
\hline 10. & Timah hitam $(\mathrm{Pb})$ & Ppm & 0,261 & 13,26 & 2,5 \\
\hline 11. & Seng $(Z n)$ & Ppm & 0,092 & 43,62 & 2,5 \\
\hline
\end{tabular}

Tabel 3. Hasil analisis kimia bata beton berlobang

\begin{tabular}{|l|l|l|r|r|r|}
\hline No. & \multicolumn{1}{|c|}{ Unsur } & Satuan & $\begin{array}{c}\text { Hasil uji } \\
\text { ekstraksi } \\
\text { TCLP }\end{array}$ & $\begin{array}{c}\text { Hasil uji } \\
\text { pada } \\
\text { sampel }\end{array}$ & PP No. 18/1999 (TCLP) $)^{6)}$ \\
\hline 1. & Sianida $(\mathrm{CN})$ & Ppm & $<0,003$ & - & 1 \\
\hline 2. & Nitrat $\left(\mathrm{HNO}_{3}\right)+$ Nitrit $\left(\mathrm{HNO}_{2}\right)$ & Ppm & 0,71 & - & 500 \\
\hline 3. & Nitrit $(\mathrm{HNO})$ & $\mathrm{Ppm}$ & $<0,043$ & - & 50 \\
\hline 4. & Arsen $(\mathrm{As})$ & $\mathrm{Ppm}$ & $<0,002$ & 4,320 & 0,2 \\
\hline 5. & Barium $(\mathrm{Ba})$ & $\mathrm{Ppm}$ & 0,04 & 87,272 & 5 \\
\hline 6. & Boron $(\mathrm{B})$ & $\mathrm{Ppm}$ & $<0,05$ & - & 100 \\
\hline 7. & Krom $(\mathrm{Cr})$ & $\mathrm{Ppm}$ & $<0,015$ & 1,545 & 0,25 \\
\hline 8. & Tembaga $(\mathrm{Cu})$ & $\mathrm{Ppm}$ & 0,0089 & 7,851 & 0,19 \\
\hline 9. & Merkuri $(\mathrm{Hg})$ & $\mathrm{Ppm}$ & 0,00031 & 0,17129 & 0,01 \\
\hline 10. & Timah hitam $(\mathrm{Pb})$ & $\mathrm{Ppm}$ & 0,083 & 4,22 & 2,5 \\
\hline 11. & Seng $(\mathrm{Zn})$ & $\mathrm{Ppm}$ & 0,083 & 38,9297 & 2,5 \\
\hline
\end{tabular}

Tabel 4. Hasil Analisis Kimia Genteng Beton

\begin{tabular}{|l|l|l|r|r|r|}
\hline No. & \multicolumn{1}{|c|}{ Unsur } & Satuan & $\begin{array}{c}\text { Hasil uji } \\
\text { ekstraksi } \\
\text { TCLP }\end{array}$ & $\begin{array}{c}\text { Hasil uji } \\
\text { pada } \\
\text { sampel }\end{array}$ & PP No. 18/1999 (TCLP) $)^{6}$ \\
\hline 1. & Sianida $(\mathrm{CN})$ & Ppm & $<0,0017$ & - & 1 \\
\hline 2. & Nitrat $\left(\mathrm{HNO}_{3}\right)+$ Nitrit $\left(\mathrm{HNO}_{2}\right)$ & Ppm & 0,40 & - & 500 \\
\hline 3. & Nitrit $\left(\mathrm{HNO}_{2}\right)$ & $\mathrm{Ppm}$ & $<0,025$ & - & 50 \\
\hline 4. & Arsen $(\mathrm{As})$ & $\mathrm{Ppm}$ & $<0,0012$ & 2,43 & 0,2 \\
\hline 5. & Barium $(\mathrm{Ba})$ & $\mathrm{Ppm}$ & 0,0225 & 49,091 & 5 \\
\hline 6. & Boron $(\mathrm{B})$ & $\mathrm{Ppm}$ & $<0,017$ & - & 100 \\
\hline 7. & Krom $(\mathrm{Cr})$ & $\mathrm{Ppm}$ & $<0,0085$ & 0,8691 & 0,25 \\
\hline 8. & Tembaga $(\mathrm{Cu})$ & $\mathrm{Ppm}$ & 0,005 & 4,4162 & 0,19 \\
\hline
\end{tabular}




\begin{tabular}{|l|l|c|c|c|c|}
\hline No. & \multicolumn{1}{|c|}{ Unsur } & Satuan & $\begin{array}{c}\text { Hasil uji } \\
\text { ekstraksi } \\
\text { TCLP }\end{array}$ & $\begin{array}{c}\text { Hasil uji } \\
\text { pada } \\
\text { sampel }\end{array}$ & PP No. 18/1999 (TCLP)6) \\
\hline 9. & Merkuri $(\mathrm{Hg})$ & Ppm & 0,00017 & 0,09635 & 0,01 \\
\hline 10. & Timah hitam $(\mathrm{Pb})$ & $\mathrm{Ppm}$ & 0,0467 & 2,37 & 2,5 \\
\hline 11. & Seng $(\mathrm{Zn})$ & $\mathrm{Ppm}$ & 0,0467 & 21,8979 & 2,5 \\
\hline
\end{tabular}

Tabel 5. Hasil Analisis Kimia Paving Block

\begin{tabular}{|c|c|c|c|c|c|}
\hline No. & Unsur & Satuan & $\begin{array}{l}\text { Hasil uji } \\
\text { ekstraksi } \\
\text { TCLP }\end{array}$ & $\begin{array}{l}\text { Hasil uji } \\
\text { pada } \\
\text { sampel }\end{array}$ & PP No. $18 / 1999$ (TCLP) $)^{6)}$ \\
\hline 1. & Sianida $(\mathrm{CN})$ & Ppm & $<0,001125$ & - & 1 \\
\hline 2. & Nitrat $\left(\mathrm{HNO}_{3}\right)+$ Nitrit $\left(\mathrm{HNO}_{2}\right)$ & Ppm & 0,2663 & - & 500 \\
\hline 3. & Nitrit (HNO2) & Ppm & $<0,0162$ & - & 50 \\
\hline 4. & Arsen (As) & Ppm & $<0,00075$ & 1,62 & 0,2 \\
\hline 5. & Barium $(\mathrm{Ba})$ & Ppm & 0,015 & 32,727 & 5 \\
\hline 6. & Boron (B) & Ppm & $<0,018$ & - & 100 \\
\hline 7. & Krom (Cr) & $\mathrm{Ppm}$ & 0,00563 & 0,5794 & 0,25 \\
\hline 8. & Tembaga $(\mathrm{Cu})$ & Ppm & 0,00334 & 2,944 & 0,19 \\
\hline 9. & Merkuri $(\mathrm{Hg})$ & Ppm & 0,000116 & 0,06423 & 0,01 \\
\hline 10. & Timah hitam $(\mathrm{Pb})$ & Ppm & 0,031 & 1,58 & 2,5 \\
\hline 11. & Seng $(Z n)$ & $\mathrm{Ppm}$ & 0,031 & 14,5966 & 2,5 \\
\hline
\end{tabular}

Tabel 6. Hasil Analisis Kimia Panel Beton

\begin{tabular}{|l|l|r|r|r|r|}
\hline No. & \multicolumn{1}{|c|}{ Unsur } & Satuan & $\begin{array}{c}\text { Hasil uji } \\
\text { ekstraksi } \\
\text { TCLP }\end{array}$ & $\begin{array}{c}\text { Hasil uji } \\
\text { pada } \\
\text { sampel }\end{array}$ & PP No. 18/1999 (TCLP) $)^{6}$ \\
\hline 1. & Sianida (CN) & Ppm & $<0,0016$ & - & 1 \\
\hline 2. & Nitrat (HNO3)+ Nitrit (HNO2) & Ppm & 0,375 & - & 500 \\
\hline 3. & Nitrit (HNO2) & Ppm & $<0,0227$ & - & 50 \\
\hline 4. & Arsen $(\mathrm{As})$ & Ppm & $<0,00106$ & 2,283 & 0,2 \\
\hline 5. & Barium $(\mathrm{Ba})$ & $\mathrm{Ppm}$ & 0,02114 & 46,1128 & 5 \\
\hline 6. & Boron $(\mathrm{B})$ & $\mathrm{Ppm}$ & $<0,0264$ & - & 100 \\
\hline 7. & Krom $(\mathrm{Cr})$ & $\mathrm{Ppm}$ & $<0,00783$ & 0,81635 & 0,25 \\
\hline 8. & Tembaga $(\mathrm{Cu})$ & $\mathrm{Ppm}$ & 0,0047 & 4,1483 & 0,19 \\
\hline 9. & Merkuri $(\mathrm{Hg})$ & $\mathrm{Ppm}$ & 0,000164 & 0,09077 & 0,01 \\
\hline 10. & Timah hitam $(\mathrm{Pb})$ & $\mathrm{Ppm}$ & 0,04386 & 2,22877 & 2,5 \\
\hline 11. & Seng $(\mathrm{Zn})$ & $\mathrm{Ppm}$ & 0,092 & 20,5697 & 2,5 \\
\hline
\end{tabular}


Hasil uji logam setelah diekstraksi pada contoh uji drill cutting, bata beton berlobang, genteng beton, paving blok dan panel beton ternyata masih di bawah batas yang ditentukan dalam Keputusan No. 04 Bappedal/09/1995, sehingga program minimisasi limbah dapat dipraktekan pada daur guna (reuse) limbah drill cutting pemboran menjadi bahan bangunan alternatif. Menurut Suseno untuk meminimalisasi meningkatnya jumlah produk drill cutting antara lain dengan memanfaatkan drill cutting menjadi suatu produk ramah lingkungan yang memenuhi syarat kesehatan, memberikan kesempatan bagi masyarakat atau investor untuk mengelola drill cutting menjadi suatu produk, menyediakan tempat penempungan drill cutting yang representatif mengacu pada rencana tata ruang wilayah serta memenuhi kelayakan teknis dan lingkungan serta memberikan kemudahan izin pengelolaan drill cutting bagi para investor/ masyarakat untuk memanfaatkan drill cutting sebagai bahan bangunan alternatif ${ }^{7}$.

Untuk melihat ketelitian pekerjaan pada ekstraksi TCLP dapat dilihat pada tabel 7. Timah hitam $(\mathrm{Pb})$ memiliki tingkat
0,031 ppm dan dalam panel beton adalah 0,04386 ppm. Presentase leaching logam timah hitam pada drill cutting, bata beton berlobang, genteng beton, paving blok dan panel beton antara $39 \%-39,36 \%$. Hal ini menunjukkan bahwa pekerjaan ekstraksi TCLP berjalan dengan baik karena persentase leaching untuk setiap komponen bangunan menunjukkan nilai yang hamper sama. Begitu juga presentase leaching untuk uji logam yang lainny pada drill cutting, bata beton berlobang, genteng beton, paving block dan panel beton menunjukkan hasil yang hampir sama.

\section{KESIMPULAN DAN SARAN}

\subsection{Kesimpulan}

Berdasarkan hasil penelitian yang dilakukan maka dapat disimpulkan:

1. Analisis ekstraksi TCLP pada drill cutting, bata beton berlobang, genteng beton, paving blok dan panel beton dibawah TCLP limit sesuai dengan satandar BAPEDAL No. Kep. 04/BAPEDAL/09/1995 dan PP No. 85/1999 untuk limbah $B_{3}$.

Tabel 7. Persentasi Leaching Komponen Bangunan

\begin{tabular}{|l|c|c|c|c|c|}
\hline \multicolumn{1}{|c|}{ Unsur } & \multicolumn{5}{c|}{ Persentase leaching } \\
\hline & Drill cutting & $\begin{array}{c}\text { Bata beton } \\
\text { berlobang }\end{array}$ & $\begin{array}{c}\text { Genteng } \\
\text { beton }\end{array}$ & Paving block & Panel beton \\
\hline Arsen (As) & 0,92 & 0,92 & 0,99 & 0,92 & 0,93 \\
\hline Barium (B) & 0,92 & 0,92 & 0,92 & 0,92 & 0,92 \\
\hline Khrom (Cr) & 19,42 & 19,42 & 19,56 & 19,43 & 19,18 \\
\hline Tembaga (Cu) & 2,27 & 2,27 & 2,26 & 2,27 & 2,26 \\
\hline Merkuri (Hg) & 3,62 & 3,62 & 3,53 & 3,61 & 3,61 \\
\hline Timah hitam (Pb) & 39 & 39 & 39 & 39,2 & 39,36 \\
\hline Seng (Zn) & 4,22 & 4,26 & 4,26 & 4,26 & 8,94 \\
\hline
\end{tabular}

pencucian terbesar dan konsentrasi tertinggi dalam ekstraksi TCLP dibandingkan dengan logam lainnya. Konsentrasi timah hitam dalam ekstraksi TCLP bata beton berlobang adalah 0,083 ppm, dalam genteng beton adalah 0,0467 ppm, paving blok adalah
2. Program minimisasi limbah sebagai prosedur dan langkah oleh sebuah perusahaan perlu

3. terus ditingkatkan guna mencapai minimisasi limbah dan dapat dipraktekan pada daur guna (reuse) limbah drilling 
cutting pemboran menjadi bahan bangunan alternatif.

4. Salah satu kunci pengembangan strategi dan kebijaksanaan pengelolaan limbah adalah meningkatkan kesadaran akan produksi bersih secara prinsip akan membawa perusahaan, kembali ketahap desain produk dengan mengeliminir sumbersumber resiko lingkungan yang bersifat fundamental terhadap pengelolaan limbah berbahaya dengan reduksi pada sumber, pendauaran ulang dan pendauaran guna.

\subsection{Saran}

1. Perlu dilakukan sosialisasi baik dalam teknologi pembuatan komponen bangunan maupun dalam penggunaannya, karena komponen bangunan yang menggunakan drill cutting merupakan komponen yang baru dikenal.

2. Agar produk yang dihasilkan tetap dalam batas yang diizinkan maka perlu pemantauan secara berkala misalnya dengan melakukan uji dari produk yang dihasilkan.

\section{DAFTAR PUSTAKA}

1. Anonim. 2006. Pemanfaatan drilling cutting dalam pembuatan komponen bahan bangunan alternatif. Kerjasama penelitian antara Pusat Litbang Permukiman dengan PT Pertamina. Bandung.

2. Khaerunisa, H.Teknologi pengolahan dan pemanfaatan batubara: Toksisitas abu terbang dan abu dasar limbah PLTU batubara yang berada di Sumatera dan Kalimantan secara biologi. http://www. tekmira.esdm.go.id/batubara/toksisitas.asp.

3. Anonim. 2008. Pemanfaatan Limbah Bahan berbahaya dan Beracun. Peraturan Menteri Lingkungan Hidup No: 02 tahun 2008.

4. Dhahiyat, Y. 2002. Pemanfaatan limbah katalis pasca perengkahan minyak residu untuk menghasilkan produk semen tersubtitusi dan filler aspal beton yang aman dan akrab lingkungan. Laporan pelaksanaan RUT VIII.2.

5. Soemarwoto, O. 2000. Atur diri sendiri: Paradigma baru pembangunan. Yogyakarta: Gajah Mada University Press.

6. Anonim. 1999. Peraturan Pemerintah Republik Indonesia No. 85 tahun 1999 tentang Perubahan atas Peraturan Pemerintah No. 18 tahun 1999 tentang Pengelolaan limbah bahan berbahaya dan beracun. Jakarta: Badan Pengendalian Dampak Lingkungan. http://www.icel.or.id/ peraturan_Pemerintah_no._85.

7. Administrator. Langkah meminimalisir limbah hasil pembakaran batubara. http:// www.esdm.go.id/berita/ batubara/44/3309. 